\title{
Modeling the effects of carbon release from the Karoo Large Igneous Province (LIP)
}

THEA HATLEN HEIMDAL ${ }^{1}$, YVES GODDÉRIS ${ }^{2}$, HENRIK SVENSEN $^{1}$ AND MORGAN JONES $^{1}$

${ }^{1}$ University of Oslo

${ }^{2}$ Géosciences Environnement Toulouse

Presenting Author: t.h.heimdal@geo.uio.no

The emplacement of the Karoo Large Igneous Province (LIP) occurred synchronously with the Toarcian crisis (ca. $183 \mathrm{Ma}$ ), which is characterized by marine and terrestrial extinctions, ocean anoxia, global warming and major carbon cycle perturbations. A marked increase in the atmospheric concentration of $\mathrm{CO}_{2}\left(p \mathrm{CO}_{2}\right)$ demonstrates significant inputs of carbon, while negative carbon isotope excursions (CIEs) attest to the involvement of a ${ }^{12} \mathrm{C}$-enriched carbon source. Sills of the Karoo LIP were emplaced into organic-rich shales in the Karoo Basin, likely leading to the generation of thermogenic carbon gases $\left(\mathrm{CO}_{2}\right.$ and $\left.\mathrm{CH}_{4}\right)$ in the order of several thousand gigatons. The presence of numerous explosion pipes and hydrothermal vent complexes rooted in the contact metamorphic aureoles suggest rapid atmospheric release of the thermogenic gases.

We have used the GEOCLIM carbon cycle model to explore the effects of carbon release from the Karoo LIP. We find that organic-rich shale affected by contact metamorphism around CAMP sills represents a likely source for ${ }^{12} \mathrm{C}$-enriched carbon, and that a pulsed release of mixed mantle- and sediment-derived carbon can explain the observed Toarcian proxy data. Importantly, an extremely isotopically depleted carbon source (e.g. methane clathrates) is not required in order to replicate the negative CIEs. Our results strengthen the case for an active involvement of the Karoo LIP in the Toarcian crisis, and that the sub-volcanic part of a LIP represents a key driver for global carbon cycle perturbations. 